\title{
Supply-Side Load Optimization After Considering Environmental Cost
}

\author{
Qian Zhang, Yajie Zhao* \\ North China Electric Power University, School of Economics and Management, Baoding, Hebei, P.R. China
}

Received: 24 June 2019

Accepted: 6 August 2019

\begin{abstract}
The wide application of renewable energy makes distributed power generation play an increasingly important role, which brings a certain influence to traditional power generation. In the overall environment of smart grid planning, reasonable optimization of load supply side will greatly reduce the cost of power generation, smooth the fluctuation of load, and improve the economy of energy utilization. The optimization of supply side load using time-of-use (TOU) could promote the optimal allocation of resources, which is conducive to the sustainable development of clean energy. This paper aimed at researching the operational mode of traditional power plant and wind power when considering the demand response TOU and considering the constraints of environmental cost, thermal power load, overall dispatching and other factors to optimize the operation mode. In this paper, a multi-objective optimization model with the objective function of minimum curtailment wind rate and maximum power generation profit was established. The effectiveness of the proposed model and the improved algorithm was verified by an example. This paper also provided some support for further research on supply-side renewable energy generation and thermal power optimization considering energy storage.
\end{abstract}

Keywords: demand response, environmental cost, multi-objective optimization, improved particle swarm optimization

\section{Introduction}

Introduction of the Supply Side

Supply Side Research

The literature [1] mentioned that the rapid growth of energy demand and limited resources have led to serious global concerns about the depletion of energy resources. Low profit margins and fierce competition have

*e-mail: yajie003@163.com prompted industrial companies to seek ways to improve operational efficiency and reduce energy costs [2]. As a promising next-generation power system, a smart grid (SG) has been proposed, which involves constructing an intelligent power transmission system by implementing bidirectional power and information flow [3]. SG is a power grid including intelligent substation, smart distribution network, smart meter, smart appliances, renewable energy, an intelligent power generation system and energy storage system [4]. SG technology has enabled investment cuts in capacity expansion, enabling the intelligent dispatch of industrial power loads to be available, and accelerating the development of renewable resources to achieve cleaner power [5]. 
Literature [6] points out that environmental issues and the prospect of an energy crisis motivated people to develop wind energy and further studied the intermittent nature of wind power. This feature of wind energy is also a major challenge for large-scale grid connections. Due to the development and utilization of wind energy, huge environmental benefits have led to increasing demand, which has higher requirements for its production reliability, operation and maintenance and the application of new technologies [7, 8]. [9] studied the interaction between wind energy and electricity market, while [10] analyzed the life cycle of wind turbines to consider their economics. However, wind power has its unstable and intermittent characteristics. Large-scale use will bring certain challenges to the safe and stable operation of the entire power system [11, 12].

Thermal power is currently the most common way of generating electricity in the world and the most mature technology. However, with the pressure brought about by economic progress, the sustainable development required for environmental protection has attracted more and more attention. Traditional power systems face different challenges. The start-stop schedule is a major component of the optimal operation of the power system, also known as unit commitment (UC). [13, 14] mentioned that the goal of $\mathrm{UC}$ is to minimize the cost of power generation.

\section{Supply-Side Load Optimization}

Many researchers have carried out many models and methods for UC problems in order to reduce the cost of traditional thermal power generating units and improve environmental efficiency $[15,16]$. UC plays an important role in traditional regulated load scheduling optimization, but it needs to be further studied as to whether it can maintain certain advantages in the face of large-scale access to the grid of renewable energy in this region. Distributed energy management is particularly important in smart grids, especially in microgrid [17]. The optimal energy management for microgrid includes economic dispatch (ED), UC, and demand side management (DSM) [18]. The emergence of microgrid is to study the optimization problem between distributed energy and traditional power generation [19, 20]. The literature [21] study considers the UC problem of renewable energy impact, that is, the problem of load optimization on the power supply side. However, for cyclically undulating loads, frequent startstop groups will increase costs. Therefore, the power side load optimization mentioned in the literature has certain limitations. This article was to plan the load of the whole unit's overall planning so that it could reduce the UC trouble caused by the cyclic floating load in a short period of time. Therefore, the variables of the start and stop of the thermal power generating unit were not considered as the objective function variables. The optimal dispatching in this paper could improve the safety and economy of regional microgrids to some extent.

\section{Introduction of Demand Side}

The increase in load demand puts a certain amount of pressure on the power supply side. In order to adapt to the growth of the load, the traditional construction cost of increasing the power equipment is huge, and the large demand for the load is also time-divided, which will inevitably result in a certain amount of waste of resources. With the development of SGrelated technologies, DR is receiving more and more attention from various industries. [22, 23] point out that DR is an important form of DSM. The DR is more like a resource that can balance the power supply and demand in the power system to transfer the load [24]. The implementation of DR could reduce power demand during peak periods. Previous research on DR shows market and reliability aspects, applicability and user satisfaction, and their application optimization methods $[25,26]$. Currently, DR is divided into incentivebased and price-based programs [27]. [28, 29] studied the economic impact of TOU. The above literature only flattened the demand curve through the price of electricity from the demand side of the grid. Although

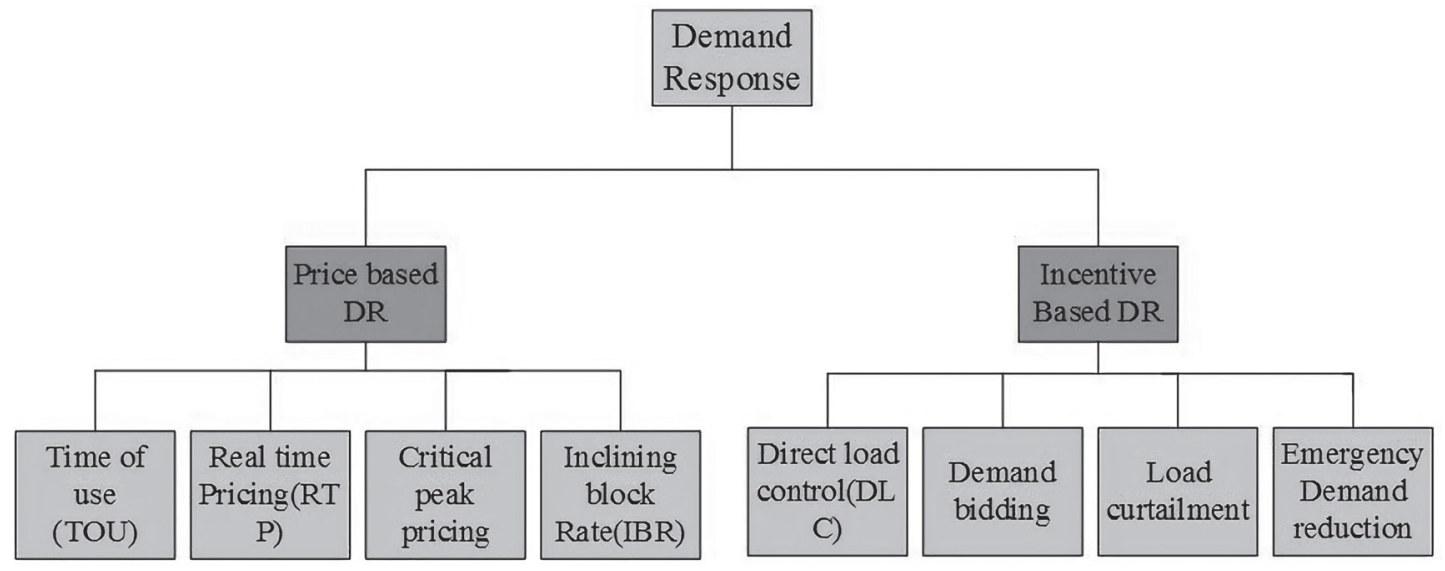

Fig. 1. Demand response classification. 
it achieved a certain effect of cutting peak and valley filling, there was not enough research on the change of the supply side affected by renewable energy. Fig. 1 is a classification diagram of the demand response.

\section{Joint Optimization Scheduling on the Supply and Demand Sides}

After the implementation of the demand response TOU electricity price measure, the demand for power load will cause the peak-to-valley load value to fluctuate less, achieving a certain degree of reverse filling, that is, the relative power consumption during the daytime peak period is relatively reduced, and the evening trough period is that the amount of electricity used will increase. This is consistent with the power generation characteristics of wind power, which reduces the wind curtailment rate of wind power generation, improves the economics of production, improves the utilization rate of clean energy production, reduces environmental pressure, and is of great significance for sustainable development. Both supply- and demand-side optimization could play a role in reducing enterprise power generation costs, reducing resource waste and improving the deep utilization of resources. Then comprehensive consideration of the optimization of the supply and demand sides should have more significant effects. The main goal of joint optimal load scheduling is to minimize the total cost of the supply and demand side [30]. [31] proposed combining economic dispatching of renewable energy with demand-side management in microgrid. However, it did not highlight the optimization of renewable energy and traditional thermal power. [32] incorporated TOU and DR into dynamic economic scheduling problems, where TOU focuses on demand side and dynamic economic scheduling issues, with a focus on supply. On the demand side, it is desirable to reduce costs by adjusting the load of demand-responsive pricing [33]. The load change after the electricity price was studied. This part of the literature did not fully consider environmental factors and the economic benefits of environmental factors, and did not maximize the economy of renewable energy, so the economics obtained were not stable enough. In this paper, the above literatures would be integrated and the environmental cost of environmental factor transformation would be taken as one of the variables in the model.

\section{Load Optimization Considering Environmental Costs}

The pressure from energy shortages has always placed a high priority on how to maximize the economics of use. The environmental pollution caused by the traditional electric energy production process of fossil energy has prompted people to continuously strive to find renewable and clean energy that can supplement or replace conventional energy. Wind energy demonstrates its advantages and does not produce pollutants such as wastewater, waste gas, and particulate dust. [34] established a cogeneration microgrid system consisting of wind turbine (WT), photovoltaic array (PV), diesel engine (DE), micro turbine (MT), fuel cell (FC) and battery (BS). Considering the operating cost and pollutant treatment cost of the microgrid system, the comprehensive benefit maximization is selected as the objective function of dynamic economic dispatch. [35] established a model of the objective function including operating cost, pollutant treatment cost and load variance, and proposed an improved particle swarm optimization algorithm to solve. However, the literature only considers certain environmental factors to study the optimization of the supply side. Although intermittent and unstable wind energy is still a challenge to the power system, it should be paid more attention than the "environmental cost" saved by traditional thermal power [36]. In the literature, the complete environmental cost of thermal power and wind power was proposed and calculated from the aspects of pollutant $\mathrm{SO}_{2}, \mathrm{NO}_{\mathrm{x}}$, $\mathrm{CO}_{2}$, $\mathrm{PM}$ value, mining transportation and thermal pollution. There was a rigorous study on environmental cost in literature, however, there was also a lack of consideration on low-load operation of thermal power units on the supply side of the stable power grid.

According to the characteristics of thermal power plants, environmental costs could be divided into the cost of preventing the production of environmental pollution and the cost of environmental pollution caused by power generation. This paper analyzed the load optimization of traditional thermal power and renewable energy wind power, so it did not calculate the cost of environmental protection equipment that has been invested in the construction of thermal power, and only considered the cost of environmental pollution caused by power generation. The cost of environmental pollution loss from the perspective of preferential use of renewable energy was calculated from the optimization of wind energy and thermal power in this paper, where the fuel cost factor could be taken as a factor of comprehensive environmental cost to improve the accuracy of the research results.

In summary, the literatures were to optimize the load of microgrid involving distributed generation of renewable energy from certain aspects, and did not fully consider the environmental factors and the environmental economics. This paper was based on the load demand after the DR, and comprehensively considered the economics of environmental cost to optimize the dispatch of the supply side, including the distributed generation of renewable energy. In this paper, short-term periodic regular load demand would be studied. The research process would be to optimize the supply and demand under the background of regional micro grid, and the economic cost of environmental factor transformation would be taken as one of the variables. In this paper, the overall planning of thermal power units was substituted for the start-stop factor, and the calculation of fuel cost factor was highlighted 
so that the established model improves the safety and stability of low-load operation during valley load period. In this way, due to the real-time load situation, the fuel feeding cost and the corresponding calorific value of oil and fuel would be converted into the load to cushion the load fluctuation. This paper established a multi-objective model with the lowest wind yield and the largest profit, and used the improved particle swarm optimization algorithm to solve. As distributed generation, only wind power was considered in this paper.

\section{Methods}

\section{Supply- and Demand-Side Considerations}

\section{Load After TOU}

After the implementation of the demand response TOU, the demand for power load will cause the peakto-valley load value to fluctuate less, achieving a certain degree of reverse filling, that is, the relative power consumption during the daytime peak period is relatively reduced, and the evening trough period is that the amount of electricity used will increase. The load change of the peak-to-valley value after the TOU price is not only related to the price of the two nodes, but also to the electricity price of other time periods.

$$
\Delta Q_{d, s}=Q_{d, s}\left[E_{s} \cdot \frac{p_{s}^{\prime}-p_{s}}{p_{s}}+\sum_{\substack{s, t \in T \\ s \neq t}} E_{t} \cdot \frac{p_{t}^{\prime}-p_{t}}{p_{t}}\right]
$$

...where $\Delta Q_{d s}$ is the load response of the user in the actual $s$ period after the TOU; $Q_{d, s}$ is the load demand for this period; $E$ is the elastic coefficient matrix; $E_{s}$ is the elastic coefficient matrix in the $s$ period; $p_{s}$ and $p_{s}^{\prime}$ are before and after TOU; $p_{t}$ and $p_{t}^{\prime}$ are electricity prices before and after the change of $t$ period; and $T$ is the number of scheduling periods.

\section{Environmental Costs}

The environmental pressure brought by thermal power can be calculated by using a certain pollution index to calculate the cost, and the environmental cost saved can be regarded as a certain economic benefit:

$$
\left\{\begin{array}{l}
C_{c 1}=\sum C_{c, s}=C_{S_{2}}+C_{C_{2}}+C_{N O_{X}}+C_{T S P}+C_{e l s e} \\
C_{c 2}=f^{\prime}\left(C_{o i l}\right) C_{o i l}+\left[1-f^{\prime}\left(C_{o i l}\right)\right] C_{o i l} \\
C_{e}=C_{c 1} \cdot \Delta Q+C_{c 2}
\end{array}\right.
$$

...where $C_{c 1}$ represents the total environmental cost of coal combustion and $C_{c 2}$ is the cost of fuel, that is, when the thermal power unit load accounts for the total capacity ratio lower than the cost of oil injection during safe operation (the thermal power generation load at the time of oil injection also offsets the investment). The amount of oil corresponds to the difference between the loads, and the load corresponding to the amount of oil is converted according to the calorific value generated by the combustion of the oil $), f^{\prime}\left(C_{o i}\right)$ is the fuel cost factor; $\mathrm{C}_{\mathrm{SO}_{2}}, C_{\mathrm{NO}_{X}}, C_{\mathrm{CO}_{2}}, C_{\mathrm{TSP}}$, and $C_{\text {else }}$ are the costs of $\mathrm{SO}_{2}, \mathrm{NO}_{\mathrm{X}}, \mathrm{CO}_{2}$, and TSP (total suspended particulate), and the cost of else factors. $C_{e}$ is the environmental cost corresponding to the change in load, and $\Delta Q$ is the load change optimized on the supply side. Cost of environmental pollution loss, from the perspective of preferential use of renewable energy, that is, reduced the cost of renewable energy generation load $\Delta Q$. Therefore, using the idea of the "penalty function" method to calculate the environmental cost into the objective function, the more the amount of thermal power generation, the more environmental costs will be reflected. In order to facilitate the calculation, this paper converted the environmental cost into the cost corresponding to the unit load, and the load of the optimized part changes linearly, so environmental cost and the optimized load were positively correlated.

\section{Objective Function}

\section{Profit from Thermal Power Generation}

$$
r_{c}=p_{c} \sum_{i=1}^{I} \sum_{\mathrm{s}=1}^{S} Q_{i, s}\left(1-\theta_{c, i}\right)-C_{f}-\sum_{i=1}^{I} O D_{c, i}
$$

In the formula, $r_{c}$ is the profit of thermal power unit; $p_{c}$ is the on-grid price of thermal power in the region; $Q_{i, s}$ is the generating power of unit $i$ at time $s ; \theta_{c, i}$ is the power consumption rate of unit $i$; $C_{f}$ is the fuel cost of the thermal power unit; and $O D_{c, i}$ refers to other costs of thermal power units, including operation and maintenance costs.

UC can optimize the operation of the system. Many literatures considered starting and stopping primers to optimize operation and reduce costs. However, the frequent start and stop of thermal power generating units not only affects the cost and increases the manpower burden, but also damages the unit, especially the coal consumption of the unit. In the continuous few days, the load shows the peak of the day, and in the certain regular cycle of the valley value at night, the frequent start and stop shows a disadvantage. So the formula can be changed to:

$$
r_{c}=p_{c} \sum_{s=1}^{S} Q_{a, s}^{c}\left(1-\theta_{c}\right)-C_{f}-O D_{a, s}^{c}
$$

In addition, different concepts of load expressions: 


$$
Q_{s, s}^{c}=Q_{n, s}^{c}(1-l)=Q_{a, s}^{c}\left(1-\theta_{c}\right)(1-l)
$$

$Q_{a s}^{c}$ is the overall planned thermal power generation load, $Q_{n, s}^{c}$ means the on-grid load, and $Q_{s, s}^{c}$ is supply load.

This paper was to optimize the dispatching of wind power and thermal power in order to research the peakto-valley load change after the TOU. It was assumed that the fluctuation trend of the load has been in a cyclical state for a short period of time, then all the thermal power generation. The units were seen as a whole to adjust the load to generate electricity. The total fuel cost under different loads is:

$$
\left\{\begin{array}{l}
C_{f}=p_{j} \sum_{i=1}^{I} f\left(Q_{i, s}\right)+f^{\prime}\left(v_{i, s}\right) \sum_{i=1}^{I} f_{0} \\
f_{i}\left(Q_{i, s}\right)=m_{i}+n_{i} Q_{i, s}+l_{i} Q_{i, s}^{2}
\end{array}\right.
$$

$\ldots$ where $C_{f}$ is the total fuel cost; $p_{j}$ is the price of coal for power and electricity; $f_{o}$ is the cost of fuel that helps stabilize the combustion of a thermal power unit under low operating load; and $v_{i, t}$ represents the ratio of unit $i$ 's operating load to unit capacity at time. The purpose of oil injection is to make the boiler burn stably and prevent the unit from safe operation accidents caused by unstable combustion caused by poor coal quality. Thermal power generator sets, different unit capacity has different unit design coal consumption, but the actual operation of the fuel used is not completely standard coal, coal quality will also affect the actual value, which cannot be fully used as the design of coal consumption as a reference standard. $m_{i}, n_{i}, l_{i}$ are the relevant parameters.

$$
\begin{gathered}
\text { Wind Power Profit } \\
r_{w}=p_{w} \sum_{s=1}^{S} Q_{a, s}^{w}\left(1-\theta_{w}\right)-O D_{a, s}^{w}
\end{gathered}
$$

...where $r_{w}$ is the profit of wind power generation; $p_{w}$ is the on-grid price of wind power in the region; $Q^{w}{ }_{a, s}$ is the generating capacity of the unit at the moment; $\theta_{w}^{a, s}$ is the self-use power rate of wind power plant; and $O D_{a, s}^{w}$ is the operation and maintenance of wind power and other costs. Same as the power supply load of thermal power:

$$
Q_{s, s}^{w}=Q_{n, s}^{w}(1-l)=Q_{a, s}^{w}\left(1-\theta_{w}\right)(1-l)
$$

...where $Q_{a, s}^{w}$ is the overall planned wind power generation load, $Q_{n, s}^{w}$ means the on-grid load, and $Q^{w}{ }_{s, s}$ is supply load.

\section{Wind Curtailment Rate}

In this paper, one of the objective functions is curtailment rate, curtailment rate $=$ curtailment air volume / (curtailment air volume + actual air volume). Since the amount of curtailment air and the actual amount of generated air are converted into the same method of generating power, the curtailment rate could also be calculated by replacing the power of both. The formula is:

$$
\varepsilon=Q_{c, s}^{w} /\left(Q_{c, s}^{w}+Q_{a, s}^{w}\right)
$$

...where $\varepsilon$ is the curtailment rate; $Q_{c, s}^{w}$ is the load corresponding to the curtailment air volume after the $s$ period optimization; and $Q^{w}{ }_{a, s}$ is wind power generation load.

\section{Multi-Objective Particle Swarm Optimization Algorithm}

\section{Multi-Objective Model}

The goal beyond multi-objective optimization (also known as multi-performance, multi-standard or vector optimization) is to minimize or maximize several objective functions simultaneously. The goal of multiobjective problems in the mathematical programming framework is to optimize various objective functions. Therefore, there is no longer a single optimal solution, but a set of non-dominated solutions [37]. The formula is:

$$
\begin{aligned}
& \min F(x)=\left(f_{1}(x), \mathrm{K}, f_{n}(x)\right)^{T} \\
& \text { s.t }:\left\{x \in R \mid g_{i}(x) \leq 0, h_{j}(x)=0\right\}
\end{aligned}
$$

...where $x$ is the solution vector of solution space $E ; F$ is the objective function vector; $n$ is the number of solution functions; $p_{i}(x)$ is the general form inequality constraint; and $h_{j}(x)$ is the general form equality constraint. Under the condition that the time-sharing price and the curtailment rate of demand response are the smallest, the model that aims to maximize the profit of thermal power and wind power is:

$$
\begin{gathered}
\min \varepsilon=\min \left(Q_{c, s}^{w} / Q_{c, s}^{w}+Q_{a, s}^{w}\right) \\
\max z=p_{c} \sum_{i=1}^{I} \sum_{s=1}^{s} Q_{a, s}^{c}\left(1-\theta_{c, i}\right)-C_{f}-\sum_{i=1}^{I} O D_{c, i}+p_{w} \sum_{s=1}^{s} Q_{a, s}^{w}\left(1-\theta_{w}\right)-O D_{w}-C_{e}
\end{gathered}
$$

\section{Particle Swarm Optimization}

The particles in the particle swarm optimization algorithm (PSO) move in the solution space, and each position in the moving process has a fitness value corresponding to it, and the smaller the fitness value is, the better [38]. The direction and distance of particle motion are determined by the velocity of the particle. The velocity is adjusted according to the movement of each particle, so that the optimal value is found in the solution space. The formula is: 


$$
\begin{gathered}
V_{i}^{t+1}=w \cdot V_{i}^{t}+c_{1} \cdot \text { rand } \cdot\left(q_{\text {besti }}^{t}-X_{i}^{t}\right)+c_{2} \cdot \text { rand } \cdot\left(g_{\text {besti }}^{t}-X_{i}^{t}\right) \\
X_{i}^{t+1}=X_{i}^{t}+V_{i}^{t+1}
\end{gathered}
$$

...where $V_{i}^{t}$ is the velocity of the $i$ th particle at the $t$ th generation; $X_{i}^{t}$ is the position of the $i$ th particle at the $t$ th generation; $g_{\text {best }}^{t}$ is the best experienced by the particle of the $i$ th particle at the $t$ th iteration position; $g_{\text {best }}^{t}$ is the best position experienced by all particles of the $i$ th particle at the $t$ th iteration; rand is a random number between 0 and $1 ; c_{1}$ and $c_{2}$ are learning factors; and $w$ is a weighting factor.

Because it is the joint optimization of the load of wind power and thermal power, a local extremum problem may occur in the process, which is similar to the basic optimization ability and convergence speed of the basic PSO. Therefore, the nonlinear change inertia weight can be used to improve PSO performance. The formula for adjusting $w$ is:

$$
w=w_{\max }-\left(w_{\max }-w_{\min }\right) * \arcsin \frac{t}{t_{\max }} * \frac{2}{\pi}
$$

...where $w_{\max }$ and $w_{\min }$ are respectively the $w$ maximum and minimum values; $t$ is the current generation number; and $t_{\max }$ is the maximum number of iterations. When $t$ is small, $w$ is close to $w_{\max }$, and the speed of $w$ is also slower, which guarantees the global optimization ability of the algorithm; as $t$ increases, $w$ decreases nonlinearly, and the speed of $w$ decreases rapidly, ensuring that the local optimization ability of the algorithm enables the algorithm to flexibly adjust the global optimization ability and local optimization ability.

\section{Constraints}

\section{Load Balancing}

$$
\left\{\begin{array}{l}
Q_{s, s}^{c}+Q_{s, s}^{w}=Q_{d} \\
Q^{\min } \leq Q_{s, s}^{c} \leq Q^{\max }
\end{array}\right.
$$

...where $Q^{\max }$ is the maximum load of unit capacity. Generally, for the safe and smooth operation of the thermal power generating unit, the long-term fullload operation is not selected to prevent the unit safety problem caused by the fluctuation of the load. The same $Q^{\text {min }}$ indicates the lowest operating load for the safety of the unit. In this paper, $v_{i, s}$ is taken as the ratio of thermal power unit load to total capacity:

$$
\left\{\begin{array}{l}
v^{\min } \leq v_{i, s} \leq v^{\max } \\
v_{i, s}^{\min } Q_{a, s}^{\max } \leq Q_{a, s}^{c} \leq v_{i, s}^{\max } Q_{c}^{\max }
\end{array}\right.
$$

...where $v_{i, s} \geq 50 \%(i=1,2,2,4,5)$ indicates that the five units must maintain a load of more than $50 \%$ at the time of $s$. The function $f^{\prime}\left(v_{i, s}\right)$ indicates that when $v_{i, s} \geq 50 \%$ is 0 , the value of $v_{i, s} \leq 50 \%$ is 1 .

$$
f^{\prime}\left(v_{i, t}\right)=\left\{\begin{array}{l}
0, v_{i, s} \geq 50 \% \\
1, v_{i, s} \leq 50 \%
\end{array}\right.
$$

According to the actual power generation operation of the thermal power plant, $70 \% \leq v_{i, s} \leq 80 \%$ is the optimal load ratio of the unit operation. At this time, the economic benefit is high, and the long-term full-load operation caused by the load fluctuation can also be prevented. Although the minimum load operation of the generator set is roughly $35 \%$, in actual operation $50 \%$ is an important node for the safe operation of the unit. This paper was to research the cost profit of $v_{i, s}$ affected by $50 \%$ of this node, so we did not go deep into the $70 \% \leq v_{i, s} \leq 80 \%$ range.

\section{Wind Power Output Constraints}

$$
\left\{\begin{array}{l}
Q_{a, s}^{w}=W_{Q} \cdot W_{P} /(3600 \eta 1 \cdot \eta 2 \cdot 1000) \\
Q_{a, s}^{w} \leq \beta_{s} T_{s} \\
\varepsilon=Q_{c, s}^{w} /\left(Q_{c, s}^{w}+Q_{a, s}^{w}\right),(0 \leq \varepsilon \leq 1)
\end{array}\right.
$$

In the formula, $\beta_{s}$ is the equivalent utilization rate in the $s$ period; $T_{s}$ is the installed capacity of the wind farm. $W_{Q}\left(\mathrm{~m}^{2} / \mathrm{h}\right)$ is air volume per hour; $W_{p}(\mathrm{pa})$ is wind pressure; and $\eta 1$ and $\eta 2$ is the relevant parameter $(\eta 1$ is the fan efficiency of 0.719 to 0.8 ; $\eta 2$ is the mechanical transmission efficiency for the V-belt drive 0.95 , for the coupling drive 0.98). Due to the influence of other technologies, policies and other factors, the paper is not a constraint. The purpose of this study is to use the minimum curtailment rate as the basic constraint. If the data ideal is likely to occur, the curtailment rate is 0 at a certain time.

\section{Environmental Cost Constraint}

$$
\begin{gathered}
0 \leq \Delta Q \leq Q_{a, s}^{w} \\
f^{\prime}\left(C_{o i l}\right)=\left\{\begin{array}{l}
0, v_{i, s} \geq 50 \% \\
1, v_{i, s} \leq 50 \%
\end{array}\right.
\end{gathered}
$$

The optimized load ceiling cannot exceed the maximum output of wind power, because the content of the study is the impact of wind energy output (also can be said that the wind rate) on the overall results. $f^{\prime}\left(C_{\text {oil }}\right)$ as a fuel cost function affects the overall environmental cost.

\section{Materials}

This study took the optimization of microgrid including thermal power and wind power in a certain area as an example. The parameter information 
Table 1.Parameters table.

\begin{tabular}{|c|c|c|c|c|c|c|c|}
\hline & MW & $f_{d i}\left(Q_{i, t}\right)$ & $O D_{i}$ & $\theta_{i} / \%$ & $l / \%$ & $p_{s}$ & $p_{c}$ \\
\hline Thermal & $5 * 600$ & 300 & 74 & 7.1 & 10 & 380 & 570 \\
\hline Wind & 300 & & 50 & 4.5 & 10 & 540 & \\
\hline Capacity & 3300 & & & & & & \\
\hline
\end{tabular}

Table 2.Environmental cost parameters.

\begin{tabular}{|c|c|c|c|c|c|c|c|}
\hline & SO2 & NOX & CO2 & CO & TSP & COAL ASH & SLAG \\
\hline EPEG & 0.33 & 2.88 & 643.89 & 0.094 & 0.144 & 39.57 & 10.79 \\
\hline PGC & 0.95 & 0.95 & 20.0 & 16.7 & 4.0 & & \\
\hline EVS & 6.0 & 8.0 & 0.023 & 1.0 & 2.2 & 0.12 & 0.1 \\
\hline
\end{tabular}

of the generator set is shown in Table 1. The second column in the table is the capacity of the unit, $f_{d i}\left(Q_{i, t}\right)$ is the standard coal consumption of thermal power, $p_{s}$ is the price of electricity sold, and $p_{c}$ is the coal price (yuan/ton). The costs associated with environmental impact factors in this area are shown in Table 2.

According to the load demand data of this area, the 24-hour load change was taken as the sample, and the utilization rate of the wind power plant was also compared and analyzed, as shown in Fig. 2. It could be seen from the figure that the demand trend of power load and the equivalent utilization rate of wind power generation are basically the reverse trend, which is beneficial to solving the problem of priority consumption of wind power. Two more prominent points could be taken as data for comparative study analysis. The equivalence ratio of wind power at the 11:00 of the sample is $26 \%$, and the equivalent rate of the sample at $4: 00$ is $76 \%$; the peak load at the two time points is exactly $3000 \mathrm{MW}$, and the valley load is $1400 \mathrm{MW}$.

For the basic calculation parameters of environmental costs, as shown in Table 2, environmental value standard $/\left(\right.$ yuan $\left.\cdot \mathrm{kg}^{-1}\right)$ refers to the environmental value corresponding to unit pollution; pollution gas capacity/( $\left.\mathrm{kg}^{-1}\right)$, the pollution equivalent value indicates the relative relationship between pollution hazard and treatment cost between different pollutants or pollution emissions; emission of per electricity generated $/(\mathrm{g} / \mathrm{kw} \cdot \mathrm{h})$ indicates the pollution discharge corresponding to the unit power generation of thermal power enterprises.

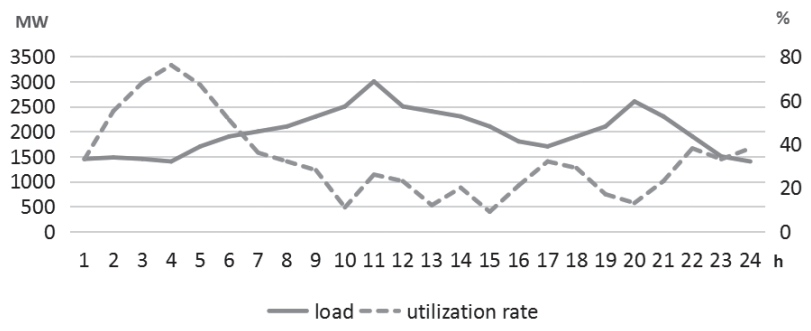

Fig. 2. Load and utilization.
Optimizing supply-side loads requires consideration of the priority use of renewable energy. Wind power output has anti-load characteristics. For this situation, the load scheduling of the demand response considering TOU can be divided into two scenarios: peak value and valley value. In this paper, the values of 4:00 and 11:00, both for load demand and the equivalent utilization rate of wind power, were in the extreme value, which could clearly show the optimization effect of the research results. After calculating the new load curve, the wind power was used first. If the objective function is satisfied, the optimization is stopped. If it is not satisfied, the constructed multi-objective model is solved by using the particle swarm algorithm. The model was calculated using Python. The two sets of solutions are load optimization of the peak and valley values after TOU.

\section{Results and discussion}

\section{Results}

Load After TOU

First, after implementing the TOU, the load change of day and night in a certain period of time would not

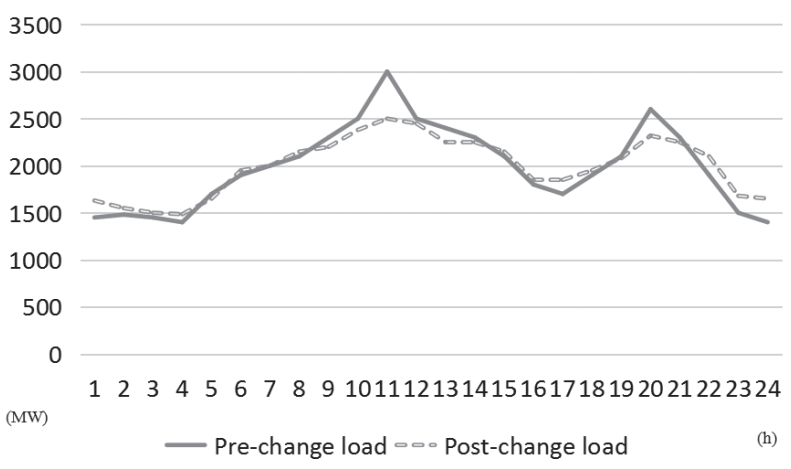

Fig. 3. Loads before and after TOU. 


\begin{tabular}{|c|c|c|c|c|c|c|c|c|c|c|c|c|c|c|c|c|}
\hline & 各 & 各 & ڤ̊ & 玄 & $\begin{array}{l}\stackrel{\hat{\sigma}}{\alpha} \\
\text { a }\end{array}$ & $\begin{array}{l}\stackrel{0}{\circ} \\
\propto\end{array}$ & $\stackrel{\circ}{\circ}$ & $\stackrel{\circ}{\circ}$ & $\stackrel{\circ}{\circ}$ & $\stackrel{\circ}{\circ}$ & $\stackrel{\circ}{\circ}$ & $\stackrel{\circ}{\infty}$ & $\stackrel{\infty}{\infty}$ & $\stackrel{\circ}{\infty}$ & $\stackrel{\circ}{\infty}$ & $0^{\circ}$ \\
\hline 3 & $\partial^{\circ}$ & $0^{\circ}$ & $\mathrm{j}^{\circ}$ & ஓें & ळे & ڤें & ふें & ふें & ڤें & ڤें & ஸें & ふें & ڤें & ஸे & ڤें & $\stackrel{े}{\text { ¿े }}$ \\
\hline$\omega$ & छे & $\stackrel{0}{0}$ & $\begin{array}{l}0 \\
0 \\
0 \\
0 \\
0\end{array}$ & 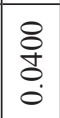 & $\begin{array}{l}\hat{\tilde{a}} \\
\hat{0} \\
\dot{0}\end{array}$ & $\begin{array}{l}\tilde{\delta} \\
\dot{0} \\
\dot{0}\end{array}$ & \begin{tabular}{l}
8 \\
\multirow{0}{0}{} \\
0 \\
0
\end{tabular} & $\begin{array}{l}\hat{\sigma} \\
\hat{\sigma} \\
\dot{0}\end{array}$ & $\begin{array}{l}\hat{8} \\
\stackrel{0}{0}\end{array}$ & $\begin{array}{l}\stackrel{0}{0} \\
\stackrel{7}{0} \\
\end{array}$ & $\begin{array}{c}\stackrel{m}{\oplus} \\
\stackrel{0}{0}\end{array}$ & 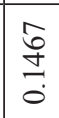 & $\begin{array}{l}8 \\
8 \\
0 \\
0\end{array}$ & $\stackrel{\tilde{\Omega}}{\underline{0}}$ & $\begin{array}{l}\widehat{0} \\
\infty \\
0 \\
0\end{array}$ & 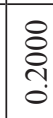 \\
\hline 8 & & 苂 & ồ & $\bar{\Xi}$ & $\begin{array}{l}\frac{n}{2} \\
8 \\
0 \\
0\end{array}$ & \begin{tabular}{|l|}
$\infty$ \\
\\
0
\end{tabular} & $\begin{array}{l}\tilde{O} \\
\tilde{\delta} \\
\dot{\delta}\end{array}$ & 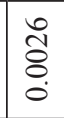 & $\begin{array}{l}\text { ते } \\
\text { ठे. } \\
\text {. }\end{array}$ & 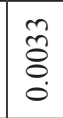 & $\begin{array}{l}\hat{\delta} \\
\text { ô } \\
0\end{array}$ & $\begin{array}{l} \\
\text { ơ } \\
8 \\
0\end{array}$ & \begin{tabular}{|l} 
\\
\\
0 \\
0 \\
0
\end{tabular} & \begin{tabular}{|l} 
\\
0 \\
0 \\
0 \\
0
\end{tabular} & $\begin{array}{l}\vec{n} \\
\stackrel{8}{0} \\
\dot{0}\end{array}$ & $\stackrel{8}{\circ}$ \\
\hline $\mathrm{N}$ & 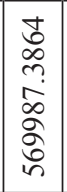 & 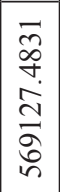 & 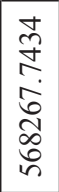 & $\begin{array}{l}\tilde{Z} \\
\delta \\
o \\
o \dot{o} \\
\delta \\
\delta \\
i \\
n\end{array}$ & $\begin{array}{l}+ \\
0 \\
\hat{n} \\
o \\
0 \\
0 \\
0 \\
0 \\
n\end{array}$ & $\begin{array}{l}n \\
n \\
\infty \\
\infty \\
0 \\
0 \\
0 \\
n\end{array}$ & 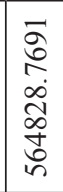 & 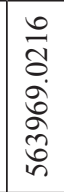 & 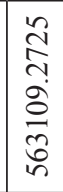 & 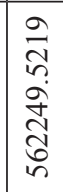 & 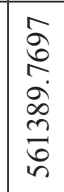 & $\begin{array}{l}\hat{n} \\
0 \\
0 \\
0 \\
0 \\
0 \\
0 \\
n\end{array}$ & 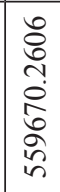 & $\begin{array}{l}\hat{\tilde{o}} \\
\tilde{n} \\
0 \\
\infty \\
\infty \\
n \\
n\end{array}$ & 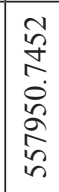 & 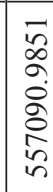 \\
\hline$\therefore$ & $\begin{array}{l}0 \\
\infty \\
\infty \\
\infty\end{array}$ & $\begin{array}{l}0 \\
\dot{0} \\
\mathbb{0} \\
\infty \\
-\end{array}$ & $\begin{array}{l}\tilde{N} \\
\tilde{f} \\
\infty\end{array}$ & $\begin{array}{l}\infty \\
\underset{J}{ \pm} \\
\stackrel{\Xi}{\Xi}\end{array}$ & 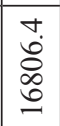 & 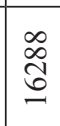 & $\begin{array}{l}0 \\
0 \\
0 \\
0 \\
n\end{array}$ & 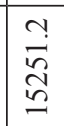 & 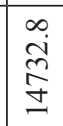 & $\begin{array}{l}\stackrel{+}{I} \\
\stackrel{I}{I}\end{array}$ & $\begin{array}{l}0 \\
0 \\
0 \\
-1\end{array}$ & $\begin{array}{l}0 \\
\stackrel{0}{\Delta} \\
\underline{n}\end{array}$ & 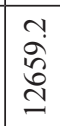 & \begin{tabular}{|l|}
$\infty$ \\
$\dot{+}$ \\
$\stackrel{I}{I}$ \\
\end{tabular} & 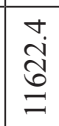 & $\stackrel{\Xi}{\Xi}$ \\
\hline$=$ & 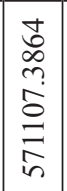 & 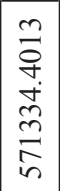 & 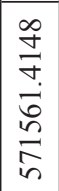 & 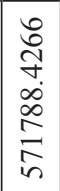 & 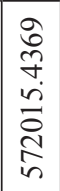 & 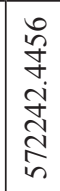 & 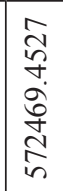 & 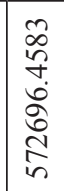 & 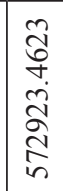 & 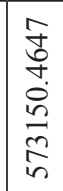 & $\begin{array}{l}n \\
\tilde{b} \\
+ \\
\tilde{\delta} \\
\tilde{n} \\
\tilde{n} \\
n\end{array}$ & $\begin{array}{l}\infty \\
0 \\
0 \\
+ \\
+ \\
0 \\
0 \\
0 \\
i n \\
i\end{array}$ & 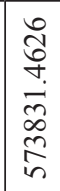 & 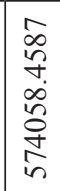 & 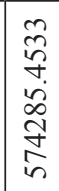 & \begin{tabular}{l} 
o \\
\multirow{J}{J}{} \\
I \\
in \\
t \\
in
\end{tabular} \\
\hline $0^{\circ}$ & & $\begin{array}{l}\infty \\
\infty \\
n \\
\infty \\
0 \\
0\end{array}$ & $\begin{array}{l}\stackrel{n}{N} \\
\infty \\
b \\
\infty \\
ٍ \\
=\end{array}$ & 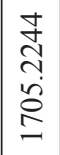 & 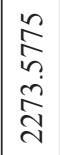 & 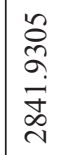 & 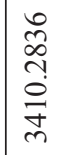 & 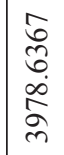 & 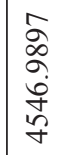 & 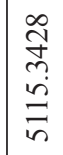 & $\begin{array}{l}\hat{\gamma} \\
\hat{\sigma} \\
\text { d. } \\
\hat{\delta} \\
\text { n}\end{array}$ & 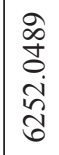 & 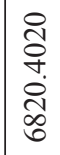 & $\begin{array}{l}\vec{n} \\
i n \\
\infty \\
\infty \\
\infty \\
\approx\end{array}$ & 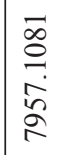 & 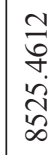 \\
\hline$u^{t}$ & $\mid \begin{array}{l}\infty \\
0 \\
0 \\
0 \\
0 \\
\vdots \\
0 \\
0\end{array}$ & 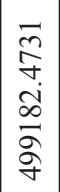 & $\begin{array}{l}\frac{J}{d} \\
\infty \\
\dot{d} \\
\stackrel{\alpha}{\alpha}\end{array}$ & 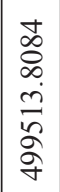 & 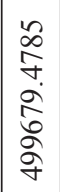 & 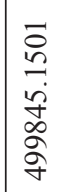 & 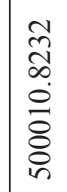 & 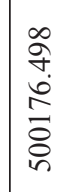 & 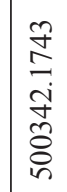 & 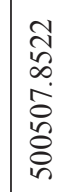 & $\begin{array}{l}0 \\
\tilde{n} \\
\tilde{n} \\
\tilde{\kappa} \\
\delta \\
\tilde{o}\end{array}$ & 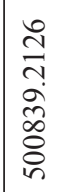 & 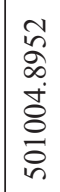 & 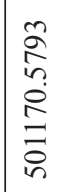 & $\begin{array}{l}n \\
\tilde{c} \\
\tilde{\delta} \\
\tilde{n} \\
\tilde{n} \\
\tilde{n}\end{array}$ & 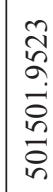 \\
\hline$\widehat{(3)}$ & 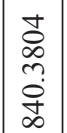 & $\mid \begin{array}{l}\overrightarrow{6} \\
0 \\
\dot{0} \\
\infty\end{array}$ & $\begin{array}{l}\vec{\delta} \\
\stackrel{+}{+} \\
\dot{+}\end{array}$ & $\begin{array}{l}\tilde{N} \\
\hat{\sim} \\
\stackrel{\dot{J}}{\infty}\end{array}$ & 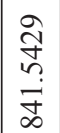 & $\begin{array}{l}0 \\
\tilde{n} \\
\infty \\
\dot{\vec{J}} \\
\infty\end{array}$ & 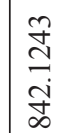 & $\begin{array}{l}\text { gे } \\
\text { J } \\
\text { J } \\
\text { d }\end{array}$ & 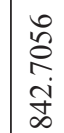 & $\begin{array}{l}\text { ปे } \\
\text { oे } \\
\text { Iे }\end{array}$ & 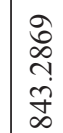 & 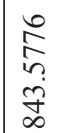 & $\begin{array}{l}\tilde{O} \\
0 \\
\infty \\
0 \\
\tilde{q} \\
\infty\end{array}$ & $\begin{array}{l}2 \\
2 \\
n \\
\stackrel{+}{+} \\
\infty\end{array}$ & 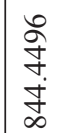 & $\underset{\infty}{\stackrel{f}{+}}$ \\
\hline z & 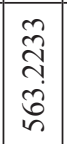 & 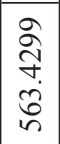 & $\begin{array}{l}0 \\
0 \\
0 \\
0 \\
0 \\
0 \\
n\end{array}$ & $\begin{array}{l}m \\
\tilde{f} \\
\infty \\
0 \\
0 \\
n\end{array}$ & $\begin{array}{l}8 \\
\text { o } \\
0 \\
0 \\
0 \\
\text { n. }\end{array}$ & $\begin{array}{l}\text { o } \\
\text { ते } \\
\text { id } \\
\text { n. }\end{array}$ & $\begin{array}{l}\text { m } \\
\text { o } \\
+ \\
0 \\
\text { f }\end{array}$ & 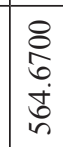 & \begin{tabular}{|c}
$\hat{0}$ \\
$\infty$ \\
0 \\
$\mathbb{d}$ \\
in
\end{tabular} & $\begin{array}{l}\text { m } \\
0 \\
0 \\
0 \\
\text { n. }\end{array}$ & 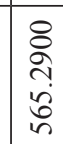 & $\begin{array}{l}\hat{\sigma} \\
\sigma \\
\sigma \\
b \\
\text { in }\end{array}$ & $\begin{array}{l}\hat{n} \\
\hat{Q} \\
\hat{0} \\
\text { n. }\end{array}$ & $\begin{array}{l}8 \\
\frac{8}{\alpha} \\
\hat{b} \\
\text { in }\end{array}$ & 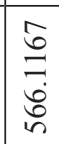 & : \\
\hline ق" & $\begin{array}{l}0 \\
\text { ̊̊ }\end{array}$ & $\begin{array}{l}\mathbb{1} \\
\hat{\sigma} \\
0 \\
0 \\
0\end{array}$ & 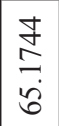 & 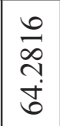 & \begin{tabular}{|l|l}
$\infty$ \\
$\infty$ \\
$\infty$ \\
0 \\
$\hat{\beta}$ \\
0
\end{tabular} & 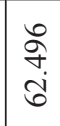 & 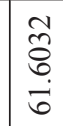 & 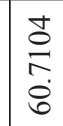 & 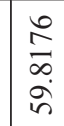 & 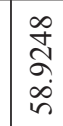 & $\begin{array}{l}\text { ते } \\
\tilde{o} \\
\infty \\
\text { in }\end{array}$ & $\begin{array}{l}\tilde{\alpha} \\
\tilde{m} \\
\tilde{n}\end{array}$ & 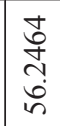 & $\begin{array}{l}0 \\
n \\
n \\
n \\
n \\
n\end{array}$ & $\begin{array}{l}\text { 悉 } \\
0 \\
+ \\
\dot{H}\end{array}$ & $\infty$ \\
\hline a. & $\mathbb{N}$ & $\Xi$ & $\stackrel{0}{\circ}$ & $\frac{7}{8}$ & $\begin{array}{c}0 \\
0 \\
0 \\
0\end{array}$ & $\frac{1}{6}$ & $\begin{array}{l}\text { तु } \\
\text { ¿ु. }\end{array}$ & \begin{tabular}{l}
$\infty$ \\
\multirow{1}{*}{} \\
బ.
\end{tabular} & $\begin{array}{l}\text { Tै } \\
\text { tै }\end{array}$ & 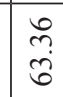 & ¿্ं & 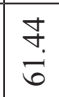 & $\begin{array}{l} \\
\text { \& } \\
8\end{array}$ & $\begin{array}{l}\tilde{2} \\
\text { nุ }\end{array}$ & $\begin{array}{l} \\
n \\
\infty \\
i n\end{array}$ & 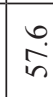 \\
\hline لَّة & $\approx$ & $\underset{\sim}{ }$ & $\approx$ & $\frac{1}{2}$ & $\vec{r}$ & $?$ & a & $\ddot{\infty}$ & $\widehat{\sigma}$ & రి & 8 & t & 3 & $\widetilde{\sigma}$ & $\vec{\sigma}$ & 8 \\
\hline$a$ & $\begin{array}{c}d \\
\stackrel{d}{d} \\
\stackrel{\sim}{d}\end{array}$ & 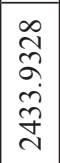 & 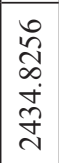 & $\begin{array}{l}\stackrel{+}{\infty} \\
\stackrel{\infty}{\sim} \\
\stackrel{\sim}{\sim} \\
\stackrel{+}{\sim}\end{array}$ & 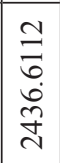 & 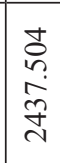 & $\begin{array}{l}\infty \\
\infty \\
\infty \\
\tilde{m} \\
\infty \\
\tilde{j} \\
\tilde{y}\end{array}$ & 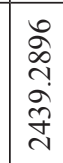 & 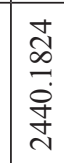 & $\begin{array}{l}\text { 令 } \\
\text { Oे } \\
\text { 竎 }\end{array}$ & $\begin{array}{l}l \\
\stackrel{\infty}{\circ} \\
\stackrel{+}{+}\end{array}$ & 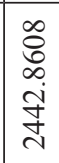 & 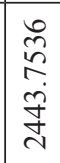 & 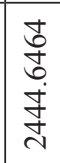 & 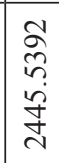 & 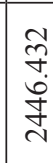 \\
\hline$a^{3}$ & 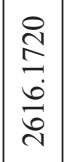 & 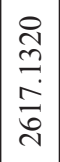 & 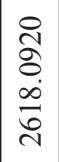 & 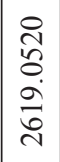 & 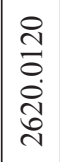 & 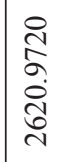 & 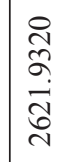 & 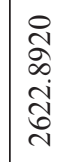 & 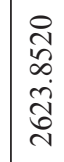 & 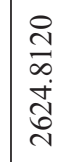 & 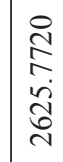 & 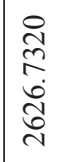 & 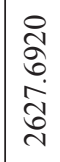 & 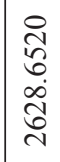 & 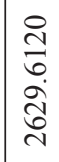 & 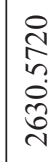 \\
\hline$a_{1}^{\circ}$ & \begin{tabular}{l}
0 \\
\multirow{-}{0}{} \\
$-\infty$
\end{tabular} & 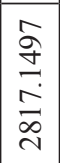 & $\begin{array}{l}\infty \\
\infty \\
\infty \\
\frac{\infty}{\infty} \\
\infty \\
\infty \\
\sim\end{array}$ & 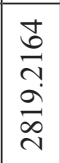 & 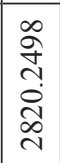 & 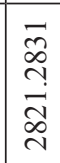 & 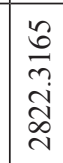 & 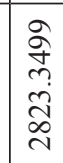 & 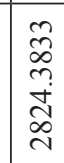 & 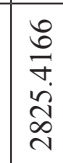 & 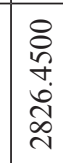 & 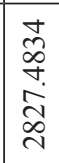 & $\begin{array}{l}\widehat{\sigma} \\
\tilde{n} \\
\infty \\
\tilde{N} \\
\infty \\
\sim\end{array}$ & 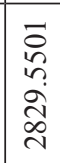 & 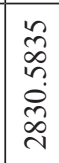 & \\
\hline $\bar{a}$ & $\begin{array}{l}8 \\
i n \\
i n\end{array}$ & $\begin{array}{l}8 \\
\text { in }\end{array}$ & \& & $\begin{array}{l}8 \\
\text { a }\end{array}$ & 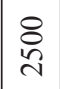 & $\begin{array}{l}\stackrel{8}{ } \\
\text { hె }\end{array}$ & $\begin{array}{l}8 \\
\text { ì } \\
\text { in }\end{array}$ & $\begin{array}{l}8 \\
\stackrel{\circ}{n} \\
\text { in }\end{array}$ & $\begin{array}{l}8 \\
\text { ì } \\
\text { in }\end{array}$ & 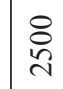 & $\begin{array}{l}\stackrel{8}{ } \\
\text { ì }\end{array}$ & $\begin{array}{l}\stackrel{8}{ } \\
\text { h్ }\end{array}$ & $\begin{array}{l}8 \\
\text { in } \\
\text { in }\end{array}$ & $\begin{array}{l}\stackrel{8}{ } \\
\text { in }\end{array}$ & 2 & \\
\hline
\end{tabular}




\begin{tabular}{|c|c|c|c|c|c|c|c|c|c|c|c|c|c|c|c|c|}
\hline & $\begin{array}{c}0 \\
0 \\
0\end{array}$ & 2 & 定 & $\therefore$ & D. & 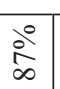 & 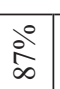 & 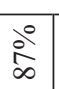 & 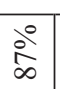 & $\stackrel{2}{0}^{\circ}$ & $\stackrel{0}{0}^{2}$ & $\therefore$ & 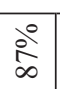 & $\begin{array}{c}\stackrel{0}{0} \\
\infty\end{array}$ & $\begin{array}{l}\stackrel{0}{0} \\
\dot{\infty}\end{array}$ & 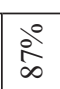 \\
\hline & $\stackrel{\circ}{\stackrel{\circ}{\circ}}$ & & & & & & $x^{\circ}$ & & & 8 & & $\stackrel{9}{=}$ & $\stackrel{\text { ஸे }}{=}$ & $\stackrel{\circ}{9}$ & लें & $\stackrel{\circ}{\circ}$ \\
\hline & $\begin{array}{l}\stackrel{8}{\circ} \\
\stackrel{0}{0}\end{array}$ & : & $\stackrel{0}{\circ}$ & $\overrightarrow{0}$ & $\because$ & $\stackrel{0}{0}$ & $\begin{array}{l}\hat{0} \\
\tilde{o} \\
0 \\
\dot{0}\end{array}$ & & & & & & & \begin{tabular}{|l|} 
\\
0 \\
$\hat{n}$ \\
0 \\
0 \\
\end{tabular} & 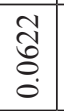 & 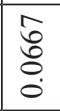 \\
\hline 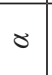 & $\Delta^{\circ}$ & & $\mathrm{d}^{\circ}$ & 1 & $\frac{\circ}{1}$ & $\div$ & $\mathrm{aे}^{\circ}$ & ठ̊ & ठे & ठ̊ & ठ̊ & ठें & ठें & ठ̊ & ठे & ठे \\
\hline$N$ & 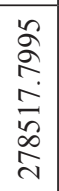 & 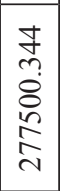 & 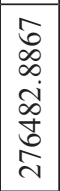 & 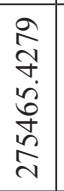 & 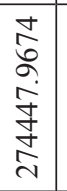 & 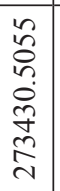 & 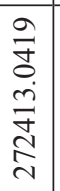 & 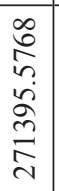 & 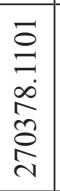 & 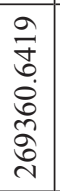 & 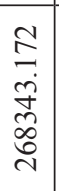 & 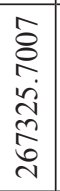 & 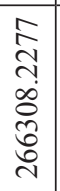 & 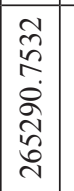 & $\begin{array}{c}\overrightarrow{\overrightarrow{0}} \\
\dot{\vec{n}} \\
\stackrel{n}{\infty} \\
m \\
m\end{array}$ & $\stackrel{\substack{n \\
m \\
m}}{n}$ \\
\hline & $\begin{array}{l}\text { 웅 } \\
\text { o }\end{array}$ & \begin{tabular}{|l|}
0 \\
$\dot{\vec{I}}$ \\
\end{tabular} & 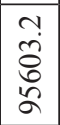 & $\begin{array}{l}\infty \\
\dot{+} \\
\infty \\
\stackrel{0}{0} \\
\alpha\end{array}$ & 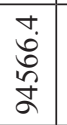 & \begin{tabular}{l}
$\infty$ \\
\multirow{2}{+}{} \\
\multirow{2}{\alpha}{}
\end{tabular} & 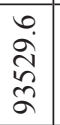 & 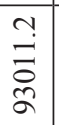 & 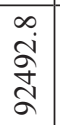 & $\stackrel{\forall}{+}$ & & $\begin{array}{l} \\
\end{array}$ & ก & , & $\underset{\sim}{\mathrm{d}}$ & 常 \\
\hline$=0$ & 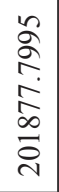 & $\mid \begin{array}{c}0 \\
0 \\
0 \\
\hat{0} \\
0 \\
-1\end{array}$ & 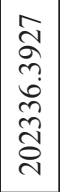 & 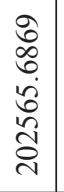 & $\begin{array}{l}\text { ते } \\
\text { ڤેे }\end{array}$ & 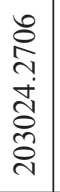 & 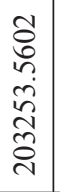 & 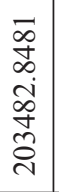 & 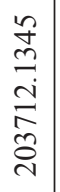 & 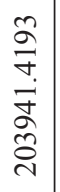 & $\underset{\vec{J}}{\stackrel{N}{c}}$ & 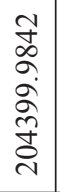 & 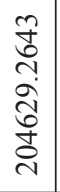 & 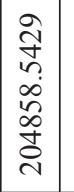 & $\begin{array}{l}\vec{m} \\
\overrightarrow{0} \\
\dot{0} \\
\stackrel{2}{2} \\
\hat{N}\end{array}$ & $\Sigma$ \\
\hline$u^{\circ}$ & & & \begin{tabular}{|l|}
8 \\
0 \\
0 \\
6 \\
0 \\
\end{tabular} & 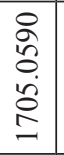 & $\vec{\sim}$ & 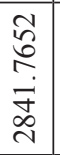 & 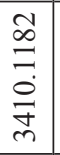 & 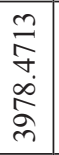 & 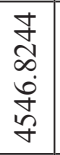 & 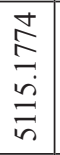 & 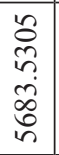 & $\begin{array}{l} \\
\infty\end{array}$ & $\begin{array}{l} \\
\mathbb{0} \\
\\
\stackrel{\AA}{1} \\
0 \\
0\end{array}$ & $\hat{a}$ & 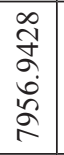 & 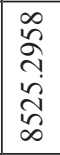 \\
\hline $0^{6}$ & 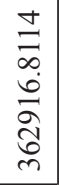 & 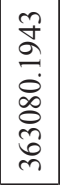 & 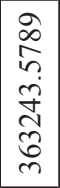 & 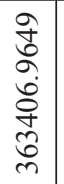 & 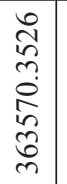 & 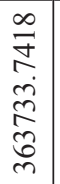 & 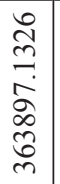 & 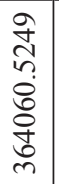 & 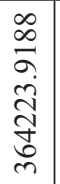 & 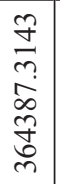 & \begin{tabular}{l}
$\dot{8}$ \\
$\stackrel{n}{n}$ \\
\multirow{0}{0}{} \\
$n$
\end{tabular} & $\begin{array}{l}\underset{+}{+} \\
\underset{d}{+} \\
\text { d }\end{array}$ & 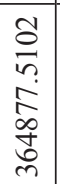 & 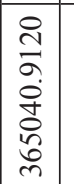 & 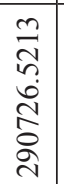 & $\begin{array}{l}0 \\
\text { oे } \\
\text { ¿ें }\end{array}$ \\
\hline ? & 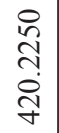 & 1 & 0 & $a$ & 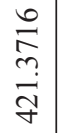 & $\tilde{\infty}^{1}$ & 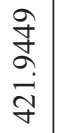 & & & & & f & f & F & f & \\
\hline 8 & 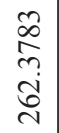 & $\begin{array}{c}0 \\
\infty \\
\infty \\
n \\
n\end{array}$ & $\sqrt{2}$ & $\hat{\infty}$ & ஜ & 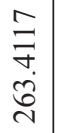 & 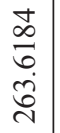 & & 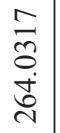 & & & $\mathrm{N}$ & $\stackrel{\sim}{*}$ & $\vec{n}$ & d్ల & \\
\hline 0 & $\begin{array}{l}\infty \\
\infty \\
\dot{m} \\
\dot{m}\end{array}$ & . & $\begin{array}{l}\infty \\
\infty \\
\infty \\
\infty \\
\dot{m} \\
\end{array}$ & $m$ & ले & & & & & & & & & & & \\
\hline 三 & $\mid \begin{array}{l}\infty \\
\infty \\
\dot{0} \\
0\end{array}$ & 10 & 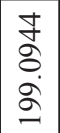 & 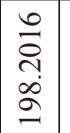 & $\begin{array}{l}\infty \\
\infty \\
0 \\
\stackrel{0}{2} \\
\hat{2}\end{array}$ & 9 & 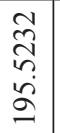 & & $\stackrel{2}{2}$ & & & 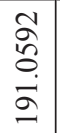 & $\curvearrowright$ & $\infty$ & $\begin{array}{l}\infty \\
\infty \\
\sim\end{array}$ & $\begin{array}{l}\infty \\
\infty \\
\stackrel{\infty}{\infty} \\
\stackrel{\infty}{-} \\
\end{array}$ \\
\hline آَ" & $\stackrel{\vec{v}}{\vec{v}}$ & $\begin{array}{l}\vec{\Delta} \\
\dot{n} \\
\vec{\sim}\end{array}$ & 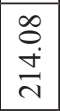 & $\begin{array}{l}\stackrel{\sim}{c} \\
\stackrel{\vec{v}}{v}\end{array}$ & c & & 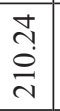 & ஷें & & & & & & స్ & ฮิ & \\
\hline & 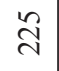 & 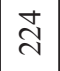 & तె & तิ & $\overline{\mathbb{N}}$ & సి & $N$ & $\sim$ & $N$ & $\sim$ & & & $\sim$ & $\sim$ & $N$ & \\
\hline ail & $\begin{array}{l}\mathcal{I} \\
\dot{D} \\
\infty\end{array}$ & 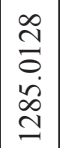 & $\begin{array}{l}0 \\
\swarrow \\
o \\
i\end{array}$ & 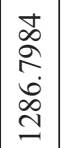 & 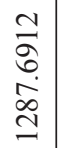 & $\begin{array}{l} \pm \\
\infty \\
\stackrel{n}{0} \\
\infty \\
\infty \\
\simeq\end{array}$ & 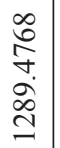 & 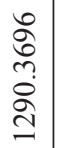 & 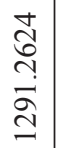 & $\begin{array}{l}\tilde{n} \\
\stackrel{n}{ } \\
\check{i} \\
\check{\beth}\end{array}$ & -1 & $\stackrel{\check{\beth}}{\beth}$ & $\begin{array}{l}\infty \\
\dot{+} \\
\stackrel{\Xi}{\Xi}\end{array}$ & $\begin{array}{l}\dot{2} \\
\grave{\beth}\end{array}$ & 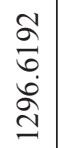 & $\tilde{\sigma}$ \\
\hline 0 & 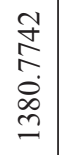 & 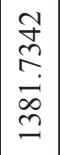 & $\mid \begin{array}{c} \\
\dot{d} \\
\infty \\
-\end{array}$ & \begin{tabular}{c}
$\infty$ \\
$\infty$ \\
\hdashline \\
\end{tabular} & 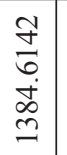 & 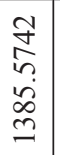 & 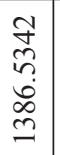 & 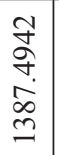 & 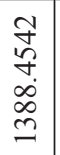 & 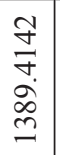 & 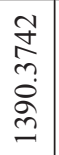 & $\simeq$ & ๙ે่ & 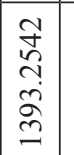 & 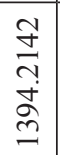 & $\begin{array}{l}\dot{2} \\
2 \\
2\end{array}$ \\
\hline$a^{2}$ & 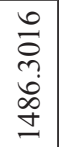 & 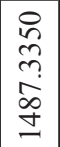 & 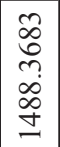 & 章 & $\vec{n}$ & 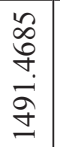 & 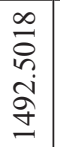 & $\therefore$ & $\begin{array}{l}0 \\
\& \\
0 \\
n \\
f \\
f\end{array}$ & $\stackrel{\dot{\sim}}{\dot{n}}$ & $\begin{array}{l}\dot{b} \\
\dot{0} \\
\dot{g} \\
\dot{I}\end{array}$ & $\overrightarrow{\dot{a}}$ & $\begin{array}{l}\vec{\infty} \\
\dot{a} \\
\dot{\Xi}\end{array}$ & 卞 & $\begin{array}{l}2 \\
\dot{8} \\
0 \\
=\end{array}$ & $\begin{array}{l}\dot{0} \\
\stackrel{2}{n}\end{array}$ \\
\hline & $\stackrel{\infty}{\infty}$ & 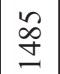 & & & $\stackrel{\infty}{\infty}$ & 离 & & & & & & & & $\begin{array}{l}n \\
\infty \\
\infty \\
\end{array}$ & $\stackrel{\infty}{\infty}$ & \\
\hline
\end{tabular}


appear to be large fluctuations. According to Formula (1), the load curve given above could be calculated to obtain the load after the influence of TOU. As shown in Fig. 3, the load curve showed a smooth trend. The load at the peak was significantly reduced, the load at the bottom was increased, and the load at the flat value fluctuates, but there was no large peak and valley. In addition, the role of TOU might also form the user's consumption habits to a certain extent, showing a stronger cycle stability. Therefore, under the influence of no other special factors such as bad weather, the load of the peak-to-valley value of the load for several consecutive days was stable after the implementation of TOU. For periodic load changes, it was more conducive to the economic dispatch of thermal power generation, and the unit was regarded as a whole to optimize and adjust, avoiding the increase of cost caused by frequent start-stop groups. The stability of the load also reduced the risk of climbing and sliding pressure caused by the large lifting load adjustment of the unit.

\section{Peak Load Distribution After TOU}

The peak load demand appeared at 11:00 of the daily working time. Although the TOU of demand response was reduced and transferred part of the load to some extent, the pressure on the power supply side was alleviated, but this time period is still the crucial period of electricity consumption. The load demand is still relatively high. In Table 3, $\alpha$ is the magnitude of the change in thermal power load, $w$ is the ratio of the overall load of wind power, and $c_{r}$ is the ratio of the overall load of thermal power. When $Q_{r}{ }^{1}=2500 \mathrm{MW}$, $\max Q_{w} \geq Q_{w}, \min \varepsilon=0, \max z=569987.3864$. As can be seen from the optimization results, the equivalent utilization rate of wind power is at a low stage in the peak demand period. Due to the small proportion of wind power in the overall load, wind power generation can be connected to the Internet to the maximum extent, and thermal power generation can also be maintained at a better economic output range. For wind power generation, the decrease of power will lead to the increase of wind curtailment rate and the decrease of profit. Therefore, the optimal state in this period is the maximum wind power output, and the objective function is relatively ideal, so there is no need to optimize the load.

\section{Valley Load Distribution After TOU}

The optimization of the supply side after TOU was focused on analyzing the output of wind and thermal power generation in the valley period. As described in the above, during the valley period, the utilization rate of wind power generation was at a high period, and the load demand was at a low value even after TOU price was implemented.

The data provided in Table 4 is the valley load after TOU. At this time, when wind power and thermal power meet the minimum curtailment rate and maximum profit, the output ratio of the total demand load has different optimization results. $Q_{\text {fuel }}$ represents load, which refers to the corresponding load value converted from the same calorific value generated in order to stabilize the combustion of thermal power units. When $Q_{d}^{2}=1485 \mathrm{MW}, v_{i s} \leq 50 \%$, in order to stabilize the operation of the unit, oil is added to support combustion. Both $C_{f}$ and $Q_{\text {fuel }}$ need to be optimized constraints. $\min \varepsilon=0, \max Q^{w}{ }_{a, s}=225 \mathrm{MW}$, it achieves the maximum utilization effect of wind power in this period, however $Q_{a, s}^{c}=1486.301608 \mathrm{MW}, \max z=278517.7995$ yuan, $v_{i, s} \leq 50 \%$, the economics and operational safety of thermal power are poor, and the profit is not the largest, so further optimization is needed. The result of $Q_{a, s}^{w}=211 \mathrm{MW}, Q_{a, s}^{c}=1500.768777 \mathrm{MW}, v_{i, s} \geq 50 \%$, $\max z=338751.071$ yuan, $\varepsilon=0.06$ is in Pareto optimal state. It satisfied the objective function, and the economics and operational safety at this time were the best, and good optimization results were obtained to support the research in this paper.

\section{Discussion}

In order to distinguish the load optimization results of peak and valley values more clearly and discuss them appropriately, the results of the two time points were compared, as shown in Table 5.

In addition, the table also lists the results before and after the load optimization of the valley before the TOU affects the change. $R_{f}$ indicates the result before optimization, and $R_{a}$ indicates the result after

Table 5.Result analysis.

\begin{tabular}{|c|c|c|c|c|c|c|}
\hline \multirow{2}{*}{} & & \multicolumn{2}{|c|}{$Q_{s}$} & \multirow{2}{*}{$\min \varepsilon$} & \multirow{2}{*}{$\max z$} & $v_{i, s}$ \\
\cline { 3 - 7 } & & $Q_{a, s}^{c}$ & $Q_{a, s}^{w}$ & & & \\
\hline \multirow{2}{*}{2500} & & 2816.1163 & 75 & 0 & 569987.38 & $\geq 50 \%$ \\
\hline \multirow{2}{*}{1485} & $R_{f}$ & 1486.3016 & 225 & 0 & 278517.79 & $\leq 50 \%$ \\
\cline { 2 - 7 } & $R_{a}$ & 1500.7687 & 211 & 0.06222 & 338751.07 & $\geq 50 \%$ \\
\hline \multirow{2}{*}{1470} & $R_{f}$ & 1468.9398 & 225 & 0 & 274665.12 & $\leq 50 \%$ \\
\cline { 2 - 7 } & $R_{a}$ & 1500.9743 & 194 & 0.13778 & 336530.17 & $\geq 50 \%$ \\
\hline
\end{tabular}


optimization. It could be seen from Table 5 that at the peak, the maximum output of wind power will also get the highest profit; while in the valley, the curtailment rate $\varepsilon=6.22 \%$, total profit $z=338751.071$, it gets a better result. Comparing the load demand at $1470 \mathrm{MW}$, even if the thermal power unit maintains the maximum profit of $50 \%$ operation, the wind curtailment rate became relatively high, and there was no stability exhibited by the load at $1485 \mathrm{MW}$. In this way, the results ensured the safe operation of the thermal power unit, the smooth scheduling of the grid load, and at the same time achieved the goal of minimizing the wind curtailment rate and maximizing profits.

It could be seen from the research results that the scheduling optimization of demand load in the valley period is more complicated than peak period. The load transfer caused by the TOU also brought great convenience to the supply side. From the optimization results, it is not difficult to find that the model proposed in this paper and the environmental cost constraints including the fuel cost factor are also suitable and feasible.

\section{Conclusions}

The following conclusions could be drawn based on the results of our research:

1. After TOU, the entire load demand curve became smoother, and the function of cutting the peaks and filling the valleys was realized to some extent. The load transfer caused by TOU also brought great convenience to the supply side. Due to the load transfer, the thermal power plant could achieve a load output of $50 \%$ or so, in the case of a higher output of wind power. The results completed the objective function of minimizing the wind curtailment rate and maximizing profits, while at the same time ensuring the safe operation of the thermal power unit and the smooth scheduling of the grid load.

2. In this paper, TOU in demand response was adopted to peak cutting and valley filling for load demand of the power grid to some extent. Then, based on the new load curve, the model of minimum wind curtailment rate and maximum profit was adopted for optimization research. In this paper, the load capacity ratio was used as one of the limiting conditions for the safe operation of thermal power units in the low-load phase of the grid. At the same time, the fuel cost coefficient with similar properties was taken as one of the factors of the model and extended to the environmental cost to calculate the grid profit. According to the research results, our proposed scheduling scheme is feasible. The optimization results have better stability and greater environmental benefits, which shows that the factors in the environmental cost cannot be ignored.

By using the multi-objective particle swarm optimization algorithm, this study maximized wind power generation while ensuring the minimum curtailment rate, and maximized the profit of high environmental benefits. This showed that the way of clean energy and the economic operation of thermal power generation was feasible, and it also showed the rationality of the research and the applicability of the actual results.

3. In this paper, wind power was only considered as a distributed energy source. With the penetration of multiple distributed energy sources, the optimization of the supply side would become more complicated. This paper also provided some ideas for future research on the relationship between the permeability of distributed energy and the optimization of the power supply side.

\section{Acknowledgements}

This research was supported by the Fundamental Research Funds for the Central Universities 2016MS127.

\section{Conflict of Interest}

The authors declare no conflict of interest.

\section{References}

1. GUARNIERI M. A lesson from past energy crises. IEEE Industrial Electronics Magazine, 10 (2), 59, 2016.

2. SCHULZE M., NEHLER H., OTTOSSON M., THOLLANDER P. Energy management in industry a systematic review of previous findings and an integrative conceptual framework. Journal Of Cleaner Production, 112, 3692, 2016.

3. CINTUGLU M.H, MOHAMMED O.A, AKKAYA K, ULUAGAC A.S. A survey on smart grid cyber-physical system testbeds. IEEE Communications Surveys Tutorials, 19 (1), 446, 2017.

4. FANG X., MISRA S., XUE G., YANG D. Smart grid - the new and improved power grid: a survey. IEEE Communications Surveys Tutorials, 14 (4), 944, 2012.

5. BLARKE M.B, JENKINS B.M SuperGrid or SmartGrid: competing strategies for large-scale integration of intermittent renewables? Energy Policy, 58 (9), 381, 2013.

6. REN G.R., LIU J.F., WAN J., GUO Y.F., YU D.R. Overview of wind power intermittency: Impacts, measurements, and mitigation solutions.Applied Energy, 204, 47, 2017.

7. DENNY E., O'MALLEY M. Wind generation, power system operation, and emissions reduction.IEEE Transactions Power System, 21, 341, 2006.

8. MARUGAN A. PLIEGO, GARCIA MARQUEZ F.P., PEREZ M PINAR. Optimal maintenance management of offshore wind farms, Energies, 9 (1), 2016.

9. SHAHMOHAMMADI A., SIOSHANSI R., CONEJO A.J, AFSHARNIA S. Market equilibria and interactions between strategic generation, wind, and storage,Applied Energy, 220, 876, 2018. 
10. BOUOU A., LAURENT A., OLSEN S.I. Life cycle assessment of onshore and offshore wind energy-from theory to application.Applied Energy, 180, 327, 2016.

11. RAHIMI E., RABIEE A., AGHAEI J., MUTTAQI K.M., NEZHAD A.E. On the management of wind power interm ittency,Renewable\&Sustainable Energy Reviews, 28, 643, 2013.

12. SIDERATO G., HATZIARGYRIOU N.D. An advanced statistical method for wind power forecasting. IEEE Transactions Power System, 22 (1), 258, 2007.

13. BERTSIMAS D., LITVINOV E., SUN X.A., ZHAO J.Y., ZHENG T.X. Adaptive Robust Optimization for the Security Constrained Unit Commitment Problem.IEEE Transactions On Power Systems, 28 (1), 52, 2013.

14. SRINICASAN D., CHAZELAS J. A priority listbased evolutionary algorithm to solve large scale unit commitment problem.IEEE International Conference on Power Con, 1746, 2004.

15. CHENG C., LIU C. Unit commitment by Lagrangian relaxation and genetic algorithms. IEEE Transactions On Power Systems, 15, 707, 2000.

16. CARRION J.M., ARROYO. A computationally efficient mixed-integer linear formulation for the thermal unit commitment problem.IEEE Transactions On Power Systems, 21 (3), 1371, 2006.

17. ZHANG Y., GATSIS N., GIANNAKIS G.B. Robust Energy Management for Microgrids With High-Penetration Renewables. IEEE Transactions On Sustainable Energy, 4 (4), 944, 2013.

18. STLUKA P.,GODBOLE D., SAMAD T. Energy management for buildings and microgrids. Proc. $50^{\text {th }}$ IEEE Conf. Decision and Control and Eur. Control Conf., 12, 12, 2011.

19. NIKNAM T.,GOLESTANEH F.,MALEKPOUR A. Probabilistic energy and operation management of a microgrid containing wind/photovoltaic/fuel cell generation and energy storage devices based on point estimate method and self-adaptive gravitational search algorithm.Energy, 43 (1), 427, 2012.

20. DAWOUD S.M., LIN X., OKBA M.I. Optimal placement of different types of RDGs based on maximization of microgrid loadability. Journal Of Cleaner Production, 168, 63, 2017.

21. PAPAVASIliOU A., OREN S.S., ROUNTREE B. Applying High Performance Computing to TransmissionConstrained Stochastic Unit Commitment for Renewable Energy Integration. IEEE Transactions On Power Systems, 30 (3), 1109, 2015

22. WERMINSKI A.,JARNUT M., BENYSEK G., BOJARSKI J. Demand side management using DADR automation in the peak load reduction.Renewable\&Sustainable Energy Reviews, 67, 998, 2017.

23. VARDAKAS J.S., ZORBA N., VERIKOUKIS C.V. A survey on demand response programs in smart grids: pricing methods and optimization algorithms. IEEE Communication Surveys And Tutorials, 17 (1), 152, 2014.

24. TORRITI J. Price-based demand side management: Assessing the impacts of time-of-use tariffs on residential electricity demand and peak shifting in northern Italy. Energy, 44, 576, 2012.
25. JANG D., EOM J., KIM M.G., RHO J.J. Demand responses of Korean commercial and industrial businesses to critical peak pricing of electricity.Journal Of Cleaner Production, 90, 275, 2015

26. BABAR M., NYUGEN P.H., CUKCUK V., KAMPHUIS I.G.R., BONGAERTS M., HANZELKA Z. The rise of AGILE demand response: enabler and foundation for change.Renewable\&Sustainable Energy Reviews, 56, 686, 2016.

27. ZHOU K., YANG S. Understanding household energy consumption behavior: the contribution of energy big data analytics.Renewable\&Sustainable Energy Reviews, 56, 810, 2016.

28. ROWLAND I.H., FURST I.M. The cost impacts of a mandatory move to time-of-use pricing on residential customers: an Ontario (Canada) case-study.Energy Efficiency, 4 (4), 571, 2011.

29. FARIA P.,VALE Z. Demand response in electrical energy supply: An optimal real time pricing approach. Energy, 36 (8), 5374, 2011

30. LU X.H., ZHOU K.L., ZHANG X.L., YANG S.L. A systematic review of supply and demand side optimal load scheduling in a smart grid environment.Journal of Cleaner Production, 203, 757, 2018.

31. ARIF A., JAVED F., ARSHAD N. Integrating renewables economic dispatch with demand side management in micro-grids: a genetic algorithm-based approach.Energy Efficiency, 7 (2), 271, 2014.

32. DEHNAVI E., ABDI H. Optimal pricing in time of use demand response by integrating with dynamic economic dispatch problem.Energy, 109, 1086, 2016.

33. ALTHAHER S., MANCARELLA P., MUTALE J. Automated demand response from home energy management system under dynamic pricing and power and comfort constraints.IEEE Transactions Smart Grid, 6 (4), 1874, 2015.

34. WU H.B., LIU X.Y., DING M. Dynamic economic dispatch of a microgrid: Mathematical models and solution algorithm.International Journal Of Electrical Power \& Energy Systems, 63, 336, 2014.

35. CHEN X.Y., LI G., LIAO Y.C., YU K. An optimal power flow model for the urban power grid considering environment cost.Automation Of Electric Power systems, 34 (15), 42, 2010.

36. XU W.L., LI Y.N., WANG H.J. Comparative analysis of the complete cost of coal-fired thermal power and wind power.Wind Energy, 06, 50, 2014 [In Chinese].

37. WANG G., TAN Z.F., TAN Q.K., YANG S.B., LIN H.Y., JI X.H., GEJIRIFU D., SONG X.Y. Multi-Objective Robust Scheduling Optimization Model of Wind, Photovoltaic Power, and BESS Based on the Pareto Principle. Sustainability, 11 (2), 2019.

38. LI X.H., JIANG C.W. Short-Term Operation Model and Risk Management for Wind Power Penetrated System in Electricity Market. IEEE Transactions On Power Systems, 26 (2), 932, 2011. 